\title{
KINEMATIC SCHEME OF EQUIPMENT TO REED HARVESTING MACHINE MRS
}

\author{
Gheorghe Ivan ${ }^{1}$, Valentin Vladut ${ }^{1}$, Radu Ciuperca ${ }^{1}$, Victor Moise ${ }^{2}$ \\ ${ }^{1}$ National Institute of Research-Development for Machines and Installations Designed to Agriculture \\ and Food Industry, Romania; ${ }^{2}$ University Politehnica of Bucharest, Romania \\ icsit@inma.ro
}

\begin{abstract}
The reed harvesting machine MRS has been designed in INMA Bucharest to correspond to environmental requirements specifically of the Danube Delta Biosphere Reservation (DDBR), regarding the harvesting of reed vegetation located on the margins of the canals and lakes, as well as the reed vegetation of the floating islands, in all ground conditions, but especially in deep water conditions. The reed vegetation is a great ecological danger for the DDBR, annual GHG emissions due to fire, in case it is not harvested at intervals of 1-2 years. MRS is the machine of a new technology that provides the reed vegetation harvesting as sheaves, throughout the year, but especially during the warm season, when the reed vegetation is still bearing leaves, the harvested material making it suitable to obtain alternative energy. To harvest this vegetation, the MRS equipment was designed to realize cutting, forming and binding the sheaves of reed vegetation in deep water conditions. For not to influence the MRS floatability, regardless of the load size, the equipment has been designed with a reduced weight, being equipped with its own float. The paper presents the kinematics scheme of the MRS equipment transmission and the correlation of its characteristics to achieve the functions, regardless of the speed of harvest. The equipment transmission is driven by a hydraulic motor with adjustable speed, being composed of a transmission with gears and levers for the cutting device and a transmission with a chain for drive the formation and binding mechanisms of the sheaves.
\end{abstract}

Keywords: renewable energy, GHC emission, reed harvester machine.

\section{Introduction}

In Romania, reed represents an inexhaustible and always available source of biomass for the inhabitants who live next to lakes, ponds and swamps in the Danube Delta. Up to this moment, this source has not been capitalized at its entire capacity, although it can represent another energy and income source for these inhabitants. On the other hand, the current global climate system is changing, the change being mainly due to GHC emissions caused by human activities.

Between 1991-2013, Romania has designated 19 wetlands of international importance, with a total area of $11,585 \mathrm{~km}^{2}$ ( $5 \%$ of the country's surface), the most important area is the Danube Delta, the surface of which is $5,800 \mathrm{~km}^{2}$, and it is divided into three areas: the Danube Delta Biosphere Reservation (DDBR), which has 20 strictly protected areas, with a total area of $509 \mathrm{~km}^{2}$, buffer zones with an area of 2,231 $\mathrm{km}^{2}$ and economic zones with a total area of $3,060 \mathrm{~km}^{2}$.

In the Danube Delta, the specific reed configurations represent the vegetation located on the margins of the canals and lakes, as well as the vegetation of the floating islands, as in Figure 1.
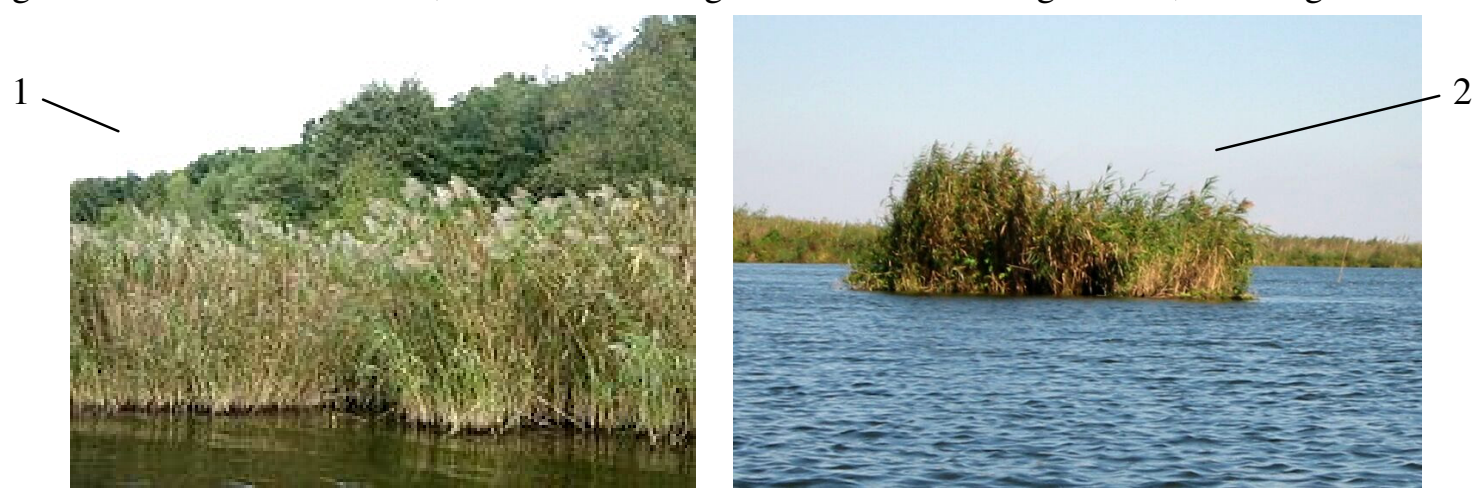

Fig. 1. Reed vegetation in the Danube Delta: 1 - on canals and lakes; 2 - floating islands [1]

This vegetation has a great potential to increase and constitutes great wealth in terms of energy, but the great threat of environmental pollution is a real "time bomb" for the Danube Delta.

This is because the vegetation is not harvested every 1-2 years, this vegetation produces reducing the amount of oxygen in the water, transforming the whole ecosystem in the dead zone. This phenomenon is very alarming for the Danube Delta Biosphere Reservetion Authority (DDBRA). 
The absence of an environmental-friendly technology, the absence of a reed harvesting machine, as well as the absence of a national strategy regarding the identification of resources generating alternative energy (biofuels) and the necessity of regenerating the reed areas, in Romania large surfaces from these areas are being burnt year after year. According to the statistics of the DDBRA it results that about $2,000 \mathrm{~km}^{2}$ are burned annually.

Elimination burning of the reed vegetation will result in annual emission reduction of carbon dioxide in the atmosphere and noxious emissions with over 2,000 t, equivalent with the pollution produced by 2 million cars a day.

The reed harvesting machine MRS, designed in INMA Bucharest, represents an environmentalfriendly technology of harvesting reed vegetation. This new technology provides harvesting throughout the year, but especially during the warm season, when the reed vegetation is still wearing leaves, the harvested material making it suitable to obtain biofuels.

The harvesting of reed vegetation in the form of sheaves will allow storage, chopping and transforming it into biofuels, through activities at stationary throughout the year, creating the possibility of increasing the employment of labor and the level of training of the human resources in disadvantaged areas of the Danube Delta.

The implementation of the new technology to harvest the reed vegetation in the Danube Delta will produce in the future preservation of environment, regeneration of reed vegetation and valorization of full potential of reed of the Danube Delta, approx. 800,000 t by year, and its use as a source of the biofuel production.

Worldwide, the reed harvesting technology provides the reed harvesting usually with specialized machines, but also harvesting with motor mowers is used, like BCS 622 [4] or the manual harvesting.

The most important manufacturers of agricultural machines do not produce reed harvesting machines. In the United Kingdom, Denmark and the Baltic States there are companies, which produce specialized machines for reed harvesting. These machines are mainly self-propelled vehicles, wheeled or tracked, but there are and a few types of multifunctional motor mowers with two or three wheels.

The self-propelled harvesting reed machines are composed usually of an equipment that cuts the reed and ties it into sheaves, a driving post equipped with a cab or not, a platform or a bunker and, in some cases, conveyors of plants or sheaves between the equipment and the hopper platform or the transport bunker.

These machines are difficult to handle due to large gauge and can not harvest the tall reed in deep water conditions. The floating of the vehicle is with low load, and the equipment is not floatable. The harvest with these machines is done by 2-6 people.

All these shortcomings are solved by the MRS machine and its new equipment, which will harvest the reed vegetation of the floating islands and on the margins of the canals and lakes in deep water conditions. The transmission of the new equipment provides the speeds required for cutting and binding the sheaves, and the size of the work organs is correlated with the height of the reed. From here, the importance of the equipment transmission and its kinematic scheme results.

\section{Materials and methods}

To harvest the reed vegetation on the margins of canals and lakes, as well as the vegetation of the floating islands, the reed harvesting machine MRS must have the access to this vegetation, to harvest in deep water conditions, to carry a big quantity of material harvested and to be easy to drive.

For this, MRS will have to be composed of a floating harvest equipment, a driving post, a storage and transport platform to transport the sheaves to storage areas, an engine, a hydrostatic transmission for displacement and operating the equipment, front and rear axles with wheels provided with tires of low pressure with large width that does not affect the reed rhizomes and ensure the floating machine with / without load, a paddle for displacement and direction of the machine in deep water, a hydraulic system for the positioning of the equipment, an electrical installation to operate the machine and drive on public roads and so on. The car will be served by three people, one to drive the car and two for taking and storage the sheaves on the transport platform.

The reed harvesting machine MRS is shown in Figure 2. 


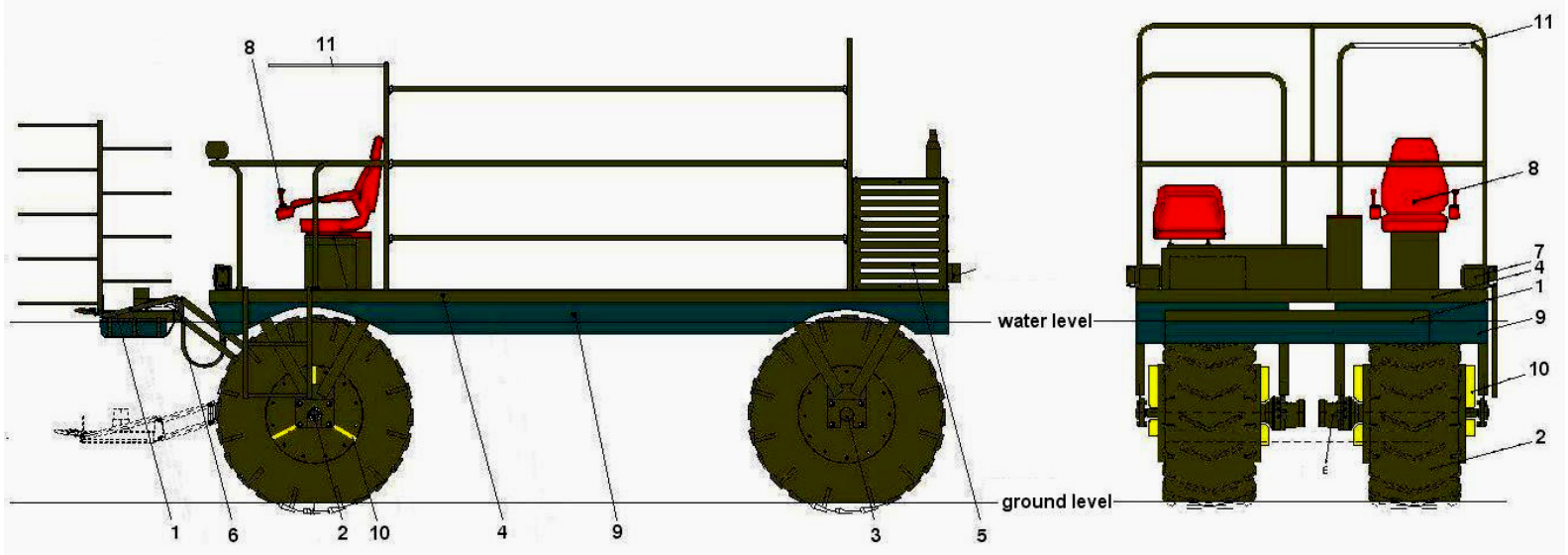

Fig. 2. Reed harvesting machine MRS: 1 - harvest equipment; 2 - front axle; 3 - rear axle; 4 - platform; 5 - engine; 6 - hydrostatic system; 7 - electrical installation; 8 -driving post; 9 - floats; 10 - paddle; 11 - parasol

The technical and functional features of MRS are the following.

- Dimensions: length $-6,260 \mathrm{~mm}$, platform width $-2,400 \mathrm{~mm}$, maximum height $-3,230 \mathrm{~mm}$.

- Laden machine weight: 2,400 daN.

- Maximum ramp: $15^{\circ}$.

- Maximum harvesting speed: $5 \mathrm{~km} \cdot \mathrm{h}^{-1}$.

- Maximum travel speed: $10 \mathrm{~km} \cdot \mathrm{h}^{-1}$.

- Hydrostatic transmission for displacement.

- Engine Kubota V2403-M-T-E3B: power - $35 \mathrm{~kW}$ at $2300 \mathrm{rpm}$, orque - $142 \mathrm{Nm}$.

- Dimensions of tire: 1,305 x $600 \mathrm{~mm}$.

- Tire air pressure: 0.3-0.5 bar.

- Flotabilitate capacity: 600 daN per tire.

The harvest equipment will have a cutting device particularly for the reed vegetation with a blade cutting the thickness greater than that of other cutting devices, splitters left and right for the height of the reed, forks left and right, a binding device of the sheaves, a mechanical-hydrostatic transmission, which operates the cutting device, and a float that assures the harvesting in deep water, as shown in Figure 3.

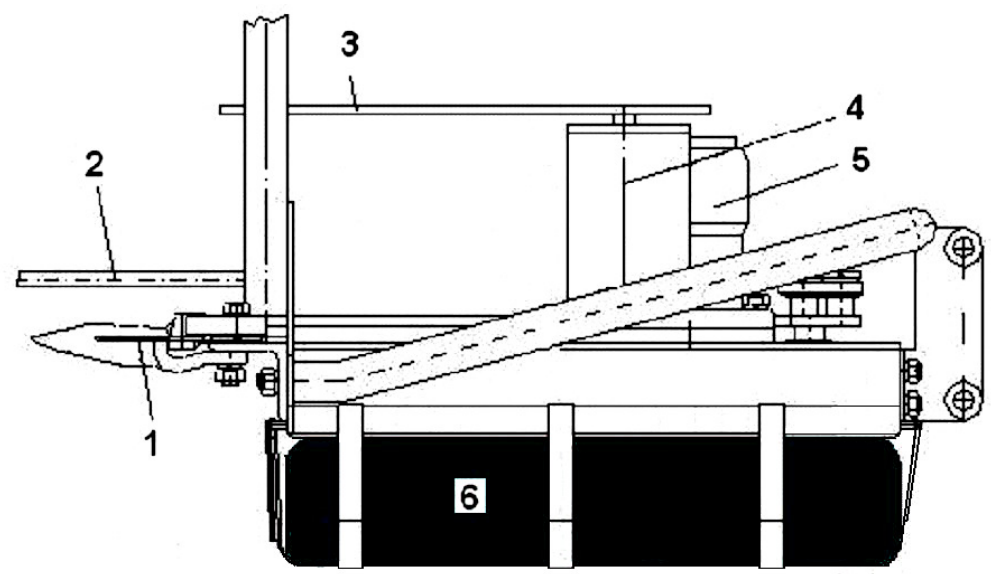

Fig. 3. Harvest equipment: 1 - cutting device; 2 - splitters left and right; 3 - forks left and right; 4 - binding device; 5 - mechanical-hydrostatic transmission; 6 - float

The reed cutting device height relative to the soil or water is achieved by adjusting the vertical position of the equipment relative to MRS.

The fork configuration and the connections were made after a study so that the cut material is transported from the cutting device to the forming and binding devices of the sheaves. Also, the height 
of the fork location has been achieved so that the height of the binding device of the sheaves is corresponding to the height of the reed.

The technical and functional features of the harvest equipment are as follows.

- Dimensions: length $-1,800 \mathrm{~mm}$, width $-1,110 \mathrm{~mm}$, height $-1,350 \mathrm{~mm}$ and $1,450 \mathrm{~mm}$ with float.

- Dimensions of cutting device: working width - 1,600 mm; distance between cutting blades and fingers $-76.2 \mathrm{~mm}$.

- Mechanical-hydrostatic transmission.

- Speed hydraulic motor drive: $153 \mathrm{rpm}$, counterclockwise.

- Speed of the cutting device drive: $351 \mathrm{rpm}$.

- Speed of the binding device, left and right crankshaft asambly and forks: 84 rpm.

- Weight: 150 daN.

- Foat volume: $0.150 \mathrm{~m}^{3}$.

- Equipment power consumption: $3 \mathrm{~kW}$.

The harvest equipment works as follows:

1. cutter device cuts the reed vegetation, guided by splitters left-right (the cutting height is adjusted by the driver);

2. forks left-right form the sheaves;

3. binder device binds the sheaves;

4. sheaves are taken by a manipulator located on the platform of the machine.

The main transmission components and the trajectory of the right forks of the MRS equipment are shown in Figure 4.

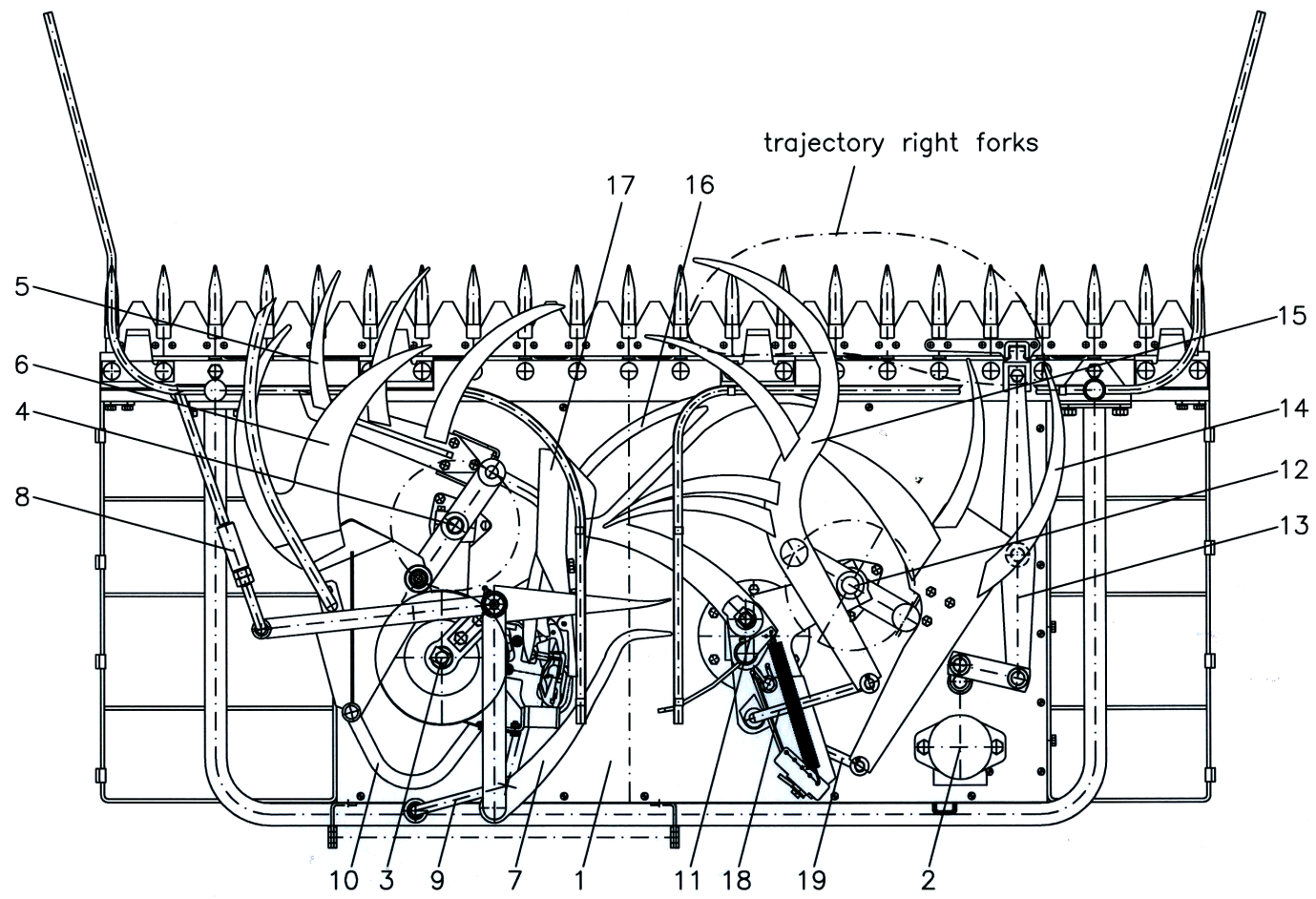

Fig. 4. Main transmission components and the trajectory of the right forks of the MRS equipment: 1 - waterproof box; 2 - hydraulic motor; 3 - binder device; 4 - left crankshaft assembly; 5 - left fork assembly I; 6 - left fork assembly II; 7 - left fork assembly III; 8 - connection I; 9 - connection II; 10 - connection III; 11 - right column assembly; 12 - right crankshaft assembly; 13 - leverage knife actuation; 14 - right fork assembly IV; 15 - right fork assembly V; 16 - needle assembly; 17 - needle guide; 18 - connection IV; 19 - connection V

All of these components are driven by a chain transmission located in a waterproof box, as in Figure 5. 


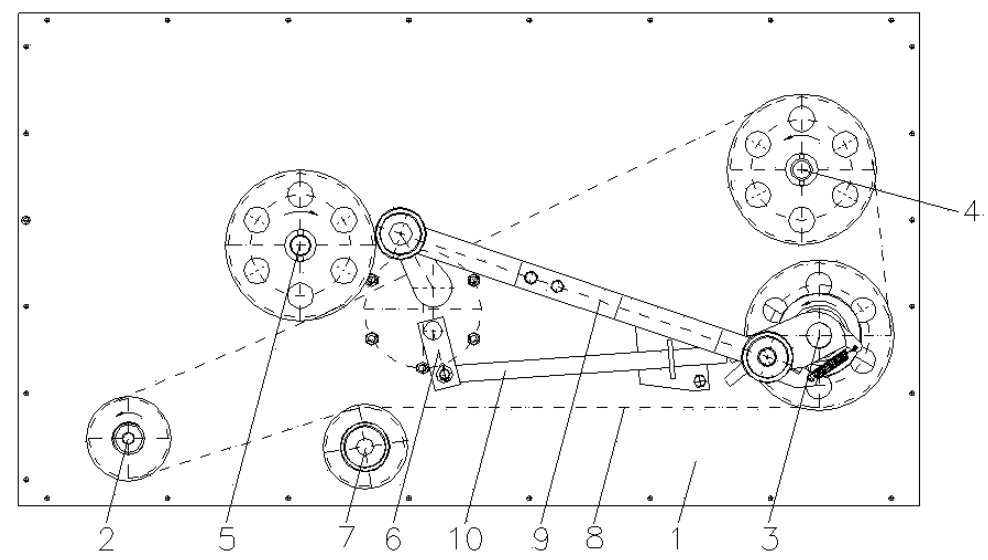

Fig. 5. Transmission with a chain inside the waterproof box: 1 - waterproof case; 2 - chain wheel driven by hydraulic motor; 3 - chain wheel and ratchet mechanism of binder device; 4 - chain wheel of left crankshaft assembly; 5 - chain wheel of right crankshaft assembly; 6 - drive mechanism for binding twine; 7 - chain wheel for chain tension; 8 - chain; 9 - drive mechanism of needle assembly;

$$
10 \text { - control pivotal assembly }
$$

We present below the kinematic scheme of this transmission. The kinematic scheme being big will be presented in two figures. The kinematic scheme of the cutting device transmission is shown in Figure 6. [2; 5]

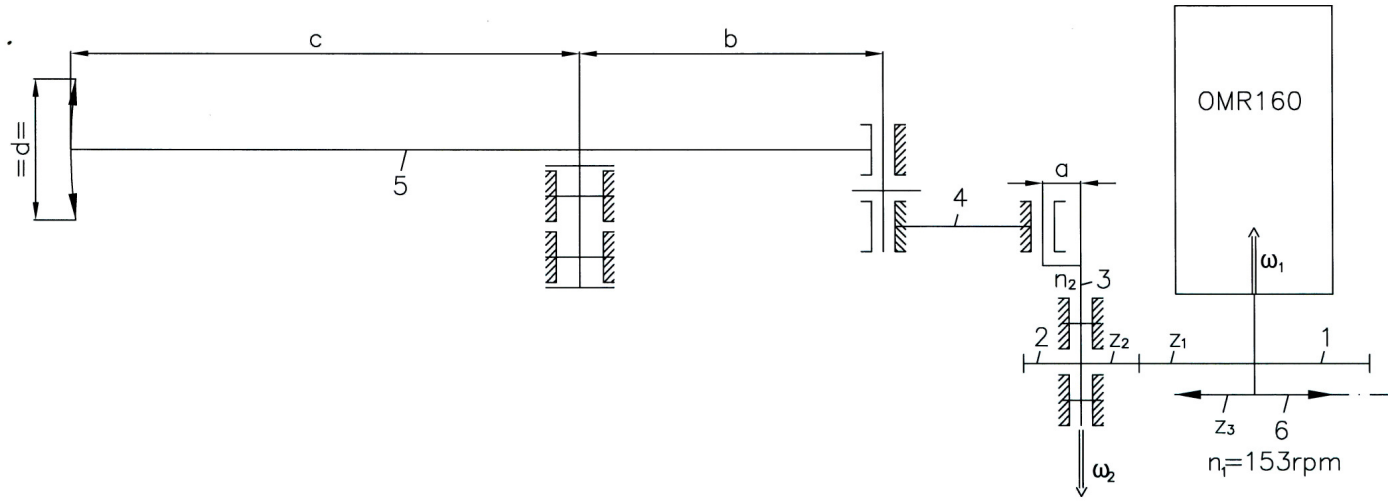

Fig. 6. Kinematic scheme of the cutting device transmission: 1 - gearwheel $1 ; 2$ - gearwheel 2; 3 - ax crankpin; 4 - connection; 5 - actuating lever; 6 - chain wheel

The functional characteristics of the cutting device, race and frequency, are calculated with the relations 1 and $2[3]$.

$$
n_{2}=\frac{z_{1}}{z_{2}} n_{1},
$$

where $n_{1}$-speed of hydraulic motor, rpm;

$n_{2}$ - speed of ax crankpin, rpm;

$z_{1}$ - number of teeth of wheel 1 , unit;

$z_{2}-$ number of teeth of wheel 2 , unit.

$$
d=\frac{c}{b} a,
$$

where $d$-race of cutting knife, $\mathrm{mm}$;

$c$ - length of arm number one of actuating lever, $\mathrm{mm}$;

$b$ - length of arm number two of actuating lever, mm;

$a$ - length of crankpin arm, mm. 
The result frequency of the cutting knife $n_{2}=350 \mathrm{rpm}$ and the race of the cutting knife $d=81 \mathrm{~mm}$. The condition $d \geq 76.2 \mathrm{~mm}$ (distance between the cutting blades and fingers) is accomplished [3]. Fig. 7.

The kinematic scheme of the transmission with a chain inside the waterproof box is presented in

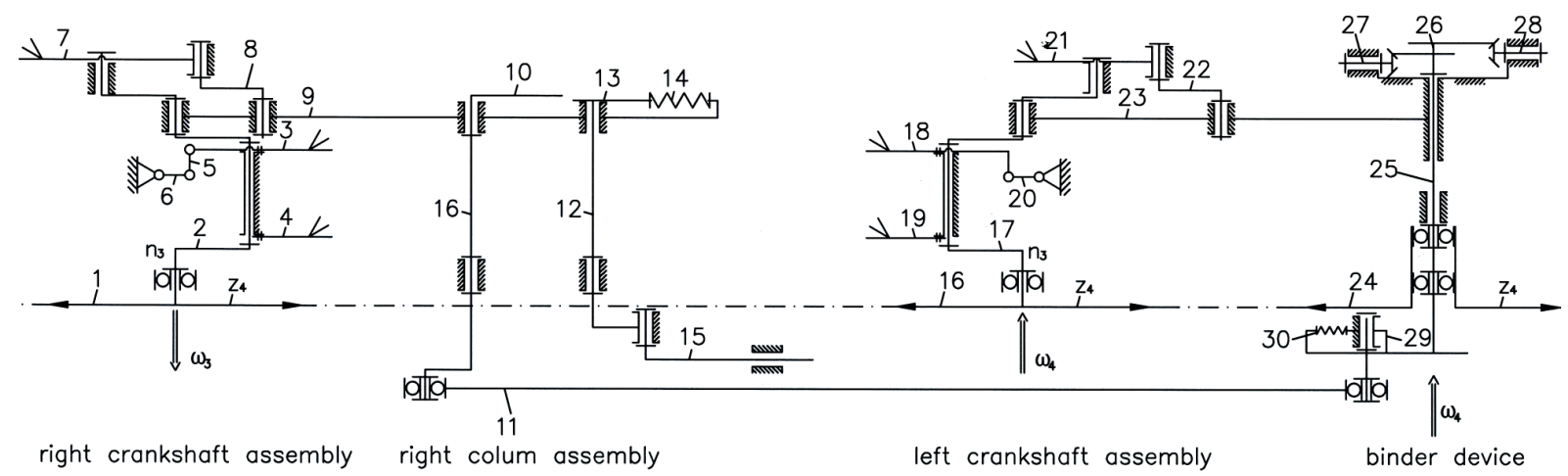

Fig. 7. Kinematic scheme of transmission with a chain inside the waterproof box: 1 - chain wheel $1 ; 2$ - right crankshaft assembly; 3 - right fork assembly IV; 4 - right fork assembly V; 5 - connection V; 6 - bearing of right column; 7 - right fork assembly V; 8 - connection IV; 9 - molded housing of right column; 10 - ax crankpin; 11 - needle assembly; 12 - drive mechanism of needle assembly; 13 - drive mechanism for the binding twine; 14 - spring I; 15 - flap assembly; 16 - chain wheel 16;

17 - left crankshaft assembly; 18 - left top fork assembly I; 19 - left top fork assembly II;

20 - connection II; 21 - left lower fork assembly I; 22 - connection III; 23 - molded housing of binder column; 24 - chain wheel 24; 25 - binder shaft assembly; 26 - cam with gears sectors; 27 - pinion shaft I; 28 - pinion shaft II; 29 - ratchet; 30 - spring II

The speed of the right crankshaft assembly is calculated with the relations 3 [3].

$$
n_{3}=\frac{z_{3}}{z_{4}} n_{1},
$$

where $n_{1}-$ speed of hydraulic motor, rpm;

$n_{3}$ - speed of right crankshaft assembly, rpm;

$z_{3}$ - teeth number of wheel 6 (Fig.6), unit;

$z_{4}-$ teeth number of wheel 1 (Fig.7), unit.

The result speed of the right crankshaft assembly $n_{3}=84 \mathrm{rpm}$. The speeds of the left crankshaft assembly and of the binder device are equal with the speed of the right crankshaft assembly.

\section{Results and discussion}

The presented kinematic scheme of the equipment to the reed harvesting machine MRS provides insight into the movement of the components and the complexity of the transmission. This complexity will produce posible risks at testing. To reduce these posible risks, the transmission design provides the possibility of adjusting the speed of the hydraulic motor so that the reed cutting, forming and binding of the sheaves are not affected regardless of the speed of harvest.

\section{Conclusions}

The project realization of the reed harvesting machine MRS will ensure the implementation of the new technology, which aim is to achieve environmental protection of the Danube Delta Biosphere Reservation through periodic reed harvesting and processing into biofuels.

The MRS testing will be completed at the end of 2017. This will validate or not the project's accuracy. 


\section{References}

1. Stuf (Reed). [online][11.12.2016] Available at: https://ro.wikipedia.org/wiki/Stuf.

2. Candea I., Bobosila M., Cotoros D. etc. Mecanica cinematica, 1998, Bucharest, Romania, pp. 89-94, 174-208.

3. Scripnic V., Babiciu P., Masini agricole, 1979, Bucharest, Romania, pp. 285-290, pp. 371-376.

4. Motor mower reaper-binder 622, prospectus from BCS. [online][11.12.2016] Available at: http://www.bcsagri.it/en/product/mowers-537a868fa2387c44627b23c7.

5. ISO 3952-2:1981, Kinematic diagrams - Graphical symbols. 